\title{
Endogenous Neurogenesis Replaces Oligodendrocytes and Astrocytes after Primate Spinal Cord Injury
}

\author{
Hong Yang, ${ }^{1}$ Paul Lu, ${ }^{1}$ Heather M. McKay, ${ }^{2}$ Tim Bernot, ${ }^{2}$ Hans Keirstead, ${ }^{3}$ Oswald Steward, ${ }^{3}$ Fred H. Gage, ${ }^{4}$ \\ V. Reggie Edgerton, ${ }^{5}$ and Mark H. Tuszynski ${ }^{1,6}$ \\ ${ }^{1}$ Department of Neurosciences, University of California, San Diego, La Jolla, California 92093-0626, ${ }^{2}$ California National Primate Research Center, \\ University of California, Davis, California 95616, ${ }^{3}$ Department of Anatomy and Neurobiology, University of California, Irvine, California 92697, ${ }^{4}$ Laboratory \\ of Genetics, Salk Institute, La Jolla, California 92037, ${ }^{5}$ Department of Physiological Science, University of California, Los Angeles, California 90095, and \\ ${ }^{6}$ Veterans Administration Medical Center, San Diego, California 92161
}

Neurogenesis has been described in various regions of the CNS throughout life. We examined the extent of natural cell division and replacement from 7 weeks to 7 months after cervical spinal cord injury in four adult rhesus monkeys. Bromodeoxyuridine (BrdU) injections revealed an increase of $>80$-fold in the number of newly divided cells in the primate spinal cord after injury, with an average of 725,000 BrdU-labeled cells identified per monkey in the immediate injury zone. By 7 months after injury, 15\% of these new cells expressed mature markers of oligodendrocytes and $12 \%$ expressed mature astrocytic markers. Newly born oligodendrocytes were present in zones of injury-induced demyelination and appeared to ensheath or remyelinate host axons. Thus, cell replacement is an extensive natural compensatory response to injury in the primate spinal cord that contributes to neural repair and is a potential target for therapeutic enhancement.

Key words: oligodendrocytes; astrocytes; proliferation; spinal cord; injury; Schwann cell

\section{Introduction}

Spinal cord injury (SCI) frequently results in permanent loss of neurological function below the injury site, although humans with partial sparing of function after injury often exhibit substantial improvement over periods of weeks to months (Little and Halar, 1985; Roth et al., 1991; Nathan, 1994; Coleman and Geisler, 2004). Putative mechanisms of spontaneous recovery over time include both compensatory behavioral strategies to maximize use of spared systems (for review, see Barbeau et al., 2002) and potential anatomical mechanisms of axonal sprouting (Goldberger, 1974; Galea and Darian-Smith, 1997; Weidner et al., 2001; Bareyre et al., 2004) or remyelination. Little is known, however, regarding the nature or extent of new cell division after SCI in mammals and about its potential to contribute to endogenous repair mechanisms.

Although few studies have examined endogenous stem-celllike responses to SCI (McTigue et al., 2001), several reports describe therapeutic grafting of stem cells or lineage-restricted precursor cells to SCI sites (McDonald et al., 1999; Vroemen et al., 2003; Hill et al., 2004; Pfeifer et al., 2004). Some of these studies report functional recovery (McDonald et al., 1999; Pfeifer et al., 2004), with suggestions that grafted stem cells differentiate into

Received Sept. 26, 2005; revised Dec. 19, 2005; accepted Dec. 20, 2005.

This work was supported by National Institutes of Health Grants NS42291 and NS047101, the California Roman Reed Bill, the California Regional Primate Research Center Base Grant, and the C. H. Neilsen Foundation. We thank Brendan Brinkman for expert technical assistance.

Correspondence should be addressed to Dr. Mark H. Tuszynski, Department of Neurosciences-0626, University of California, San Diego, 9500 Gilman Drive, La Jolla, CA 92093. E-mail: mtuszyns@ucsd.edu.

DOI:10.1523/JNEUROSCI.4070-05.2005

Copyright $\odot 2006$ Society for Neuroscience $\quad$ 0270-6474/06/262157-10\$15.00/0 glial cells, including astrocytes or oligodendrocytes. To date, however, no studies have examined new cell division after primate SCI and the potential of this mechanism to contribute to natural repair. Given the modest extent of natural recovery from mammalian SCI, this study explored the hypothesis that cell division after primate $\mathrm{SCI}$ is primarily limited to inflammatory cell lineages. Unexpectedly, we find extensive generation of new cells expressing mature markers of astrocytes and oligodendrocytes at extended time points after primate SCI.

\section{Materials and Methods}

Four adult male rhesus monkeys underwent right-sided cervical spinal cord transection lesions (Table 1); one intact monkey was also studied. Bromodeoxyuridine $(\mathrm{BrdU})\left(50 \mathrm{mg} \cdot \mathrm{kg}^{-1} \cdot \mathrm{d}^{-1}\right)$ was injected daily on each of the first $5 \mathrm{~d}$ after injury. After survival periods of 7 weeks to 7 months, the number and fate of newly dividing cells were quantified in the spinal cord. Double- and triple-confocal immunolabeling were used to colocalize BrdU with multiple cell-specific markers and to quantify cells using stereological methods.

Subjects. Five male rhesus monkeys were subjects of the study (mean age, $9.8 \pm 1.56$ years; range, $6-14$ years of age). All animals were housed at the California National Primate Research Center, and animal care procedures adhered to the Association for Assessment and Accreditation of Laboratory Animal Care and institutional guidelines.

Spinal cord lesions. Monkeys were preanesthetized with $10 \mathrm{mg} / \mathrm{kg}$ ketamine intramuscularly, intubated, and anesthetized with $1.5-2.5 \%$ isofluorane. All responses to stimuli (eyelid flutter, forepaw pressure) were verifiably absent before proceeding with surgery. A dorsal laminectomy was performed from C5 to C7, and unilateral spinal cord lesions were placed as follows: subject 1 underwent a transection lesion of $30 \%$ of the left hemicord at C7, sparing the most $2.5 \mathrm{~mm}$ of medial tissue. (The normal width of the spinal cord at this level is $8-10 \mathrm{~mm}$.) Subject 2 
Table 1. Experimental subjects

\begin{tabular}{|c|c|c|c|c|c|}
\hline \multirow{2}{*}{$\begin{array}{l}\text { Subject } \\
\text { no. }\end{array}$} & \multirow{2}{*}{$\begin{array}{l}\text { Age } \\
\text { (year) }\end{array}$} & Lesion & \multirow{2}{*}{$\frac{\text { Lesion }}{\text { Volume }}$} & \multirow{2}{*}{$\frac{\text { Lesion }}{\text { Level }}$} & \multirow{2}{*}{$\begin{array}{l}\text { After lesion } \\
\text { Time }\end{array}$} \\
\hline & & Type & & & \\
\hline 1 & 6.8 & Subhemisection & $14 \mathrm{~mm}^{3}$ & C7 & 7 weeks \\
\hline 2 & 13.4 & Hemisection & $62 \mathrm{~mm}^{3}$ & C6 & 9 weeks \\
\hline 3 & 8.2 & Subhemisection & $35 \mathrm{~mm}^{3}$ & C7 & 15 weeks \\
\hline 4 & 8.5 & Subhemisection & $38 \mathrm{~mm}^{3}$ & C6 & 29 weeks \\
\hline 5 & 14.2 & Intact & $\mathrm{N} / \mathrm{A}$ & $\mathrm{N} / \mathrm{A}$ & 18 weeks \\
\hline
\end{tabular}

All subjects were male. N/A, Not applicable.

underwent a complete right-sided hemisection at C6. Subject 3 underwent a transection lesion of $50 \%$ of the left hemicord at C7, sparing the most $1.5 \mathrm{~mm}$ of medial tissue. Subject 4 underwent transection of $65 \%$ of the left hemicord at C6. (Various lesion sizes were performed as part of model development for future regeneration studies.) Lesion extent in each subject is shown in supplemental Figure 2 (available at www. jneurosci.org as supplemental material). Lesions were made under direct microscopic guidance using a \#11 knife blade. After lesion completion, the overlying dura, muscle, and skin were separately sutured and closed. Antibiotics analgesics and supportive care were provided until subjects were able to move freely about the home cage (3-4 d). Bowel and bladder dysfunction did not occur. Postoperatively, subjects exhibited longlasting paralysis of the arm on the affected side and transient paralysis of the affected leg that gradually improved after 4-6 weeks, as reported previously after cervical hemisection lesions in primate (Lassek and Anderson, 1961; Galea and Darian-Smith, 1997).

$B r d U$ administration. The thymidine analog BrdU was used to label proliferating cells after SCI. BrdU (50 mg/kg in sterile saline; Sigma, St. Louis, MO) was injected intravenously daily, for 5 consecutive days, beginning $1 \mathrm{~d}$ after lesion. Thus, the examined proliferative response focused on cell genesis occurring within several days of SCI in the primate.

Tissue processing and immunocytochemistry. Subjects were initially sedated with $10 \mathrm{mg} / \mathrm{kg}$ intramuscular ketamine and deeply anesthetized with pentobarbitol ( $\sim 60 \mathrm{mg} / \mathrm{kg}$, i.v.) before being killed. All reflex responses to cutaneous stimulation were verifiably absent before transcardial perfusion for 2 min with $1 \%$ paraformaldehyde, immediately followed by $1 \mathrm{~h}$ of perfusion with $4 \%$ paraformaldehyde in $0.1 \mathrm{~m}$ phosphate buffer, $\mathrm{pH} 7.4$, at $4^{\circ} \mathrm{C}$. Cords were then postfixed in $4 \%$ paraformaldehyde for $6-12 \mathrm{~h}$ and $10 \%$ glycerol for $24 \mathrm{~h}$, followed by $20 \%$ glycerol as the final fixative. Spinal cords were removed and blocked in the coronal plane. Serial coronal sections were cut on a freezing microtome set to $40 \mu \mathrm{m}$.

For BrdU immunocytochemistry, sections were pretreated with $2 \mathrm{~N}$ $\mathrm{HCl}$ at $40^{\circ} \mathrm{C}$ for $30 \mathrm{~min}$ and rinsed in TBS, and nonspecific antigen binding was blocked in solution containing TBS, $5 \%$ normal goat serum, and $0.25 \%$ Triton X-100 (TBS ++ ) for $1 \mathrm{~h}$. Sections were subsequently incubated in rat anti-BrdU (1:400 in TBS++; Serotec, Oxford, UK) at $4^{\circ} \mathrm{C}$ for $48 \mathrm{~h}$. Sections were rinsed in TBS and incubated in Alexa 488conjugated goat anti-rat IgG (in TBS containing 3\% normal goat serum and $0.25 \%$ Triton X-100; 1:200; Invitrogen, Eugene, OR) for $2.5 \mathrm{~h}$. After rinsing in TBS, sections were mounted onto slides, allowed to half-dry, and coverslipped using Fluoromount G (Southern Biotechnology, Birmingham, AL).

To determine the fate of newly born cells after SCI, double-fluorescent immunolabeling was performed, combining BrdU labeling with one of the cell-specific phenotypic markers listed below. For double immunofluorescence, sections were pretreated with $\mathrm{HCl}$ as described above and incubated with BrdU antibody mixed with one of the following antibodies in TBS ++ at $4^{\circ} \mathrm{C}$ for $48 \mathrm{~h}$ : mouse anti-neuron-specific nuclear protein (NeuN) monoclonal antibody (vertebrate neuron-specific nuclear protein, for neurons; 1:250; Chemicon, Temecula, CA), mouse antiMAP2 (microtubule-associated protein 2) monoclonal antibody (for neurons; $1: 10,000$, Chemicon); mouse anti- $\beta$-III-tubulin monoclonal antibody, (tubulin, $\beta$ III isoform, for neurons; 1:750; Chemicon); rabbit anti-IBA1 polyclonal antibody (ionizing calcium-binding adapter molecule, for macrophages and microglia; 1:1000; generous gift from Dr. Imai, National Institution of Neuroscience, Tokyo, Japan); rabbit anti- glial fibrillary acid protein (GFAP) polyclonal antibody (for astrocytes; 1:750; Dako, High Wycombe, UK); mouse anti-human p75 monoclonal antibody (low-affinity neurotrophin receptor, for Schwann cells; 1:100; a generous gift from Dr. Bothwell, University of Washington, Seattle, WA); rabbit anti-NG2 polyclonal antibody (chondroitin sulfate proteoglycan, for oligodendroglial precursor cells, Schwann cells, or macrophages; 1:500; a generous gift from Dr. Stallcup, The Burnham Institute, La Jolla, CA) and mouse anti-von Willebrand factor (vWF) (for endothelia; Chemicon). For BrdU and NG2 double immunolabeling, antibody incubation was conducted before $\mathrm{HCl}$ treatment. Sections were developed using a mixture of Alexa 488-conjugated goat anti-rat IgG and Alexa 568-conjugated goat anti-rabbit or goat anti-mouse IgG (in TBS containing 3\% normal goat serum and $0.25 \%$ Triton X-100; $1: 200$; Invitrogen) for $2.5 \mathrm{~h}$. To specifically label mature oligodendrocytes, mouse anti-adenomatous polyposis coli (APC) monoclonal antibody (tumor suppressor gene product, clone CC1; 1:400; Oncogene Research Products, Cambridge, MA) was used (Bhat et al., 1996). Because APC also labels some astrocytes, BrdU/APC/GFAP triple labeling was used to clearly distinguish oligodendrocytes from astrocytes (McTigue et al., 2001): cells that were BrdU+/APC+/GFAP - were identified as oligodendrocytes. Myelin was labeled with mouse anti-myelin oligodendrocyte-specific protein monoclonal antibody (MOSP; 1:500; Chemicon). MOSP is a marker for central myelin and oligodendrocytes at a stage of development in which oligodendrocytes are elaborating processes and initiating myelin membrane sheet formation (Dyer and Matthieu, 1994). Axons were immunofluorescently labeled using rabbit anti-neurofilament $200 \mathrm{kDa}$ (1:500; Chemicon). Apoptosis was detected using both Nissl and bisbenzimide (Hoechst 33342; Invitrogen) staining to assess nuclear fragmentation.

For electron microscopy, tissue sections were postfixed in $4 \%$ glutaraldehyde in $0.1 \mathrm{M}$ phosphate buffer, $\mathrm{pH} 7.4$, for $10 \mathrm{~d}$, rinsed in $0.1 \mathrm{M}$ cacodylate buffer, $\mathrm{pH} 7.4$, for $30 \mathrm{~min}$, postfixed in $0.5 \% \mathrm{OsO}_{4}$ for $30 \mathrm{~min}$, dehydrated in ascending alcohols, embedded in Spurrs resin (Electron Microscopy Sciences, Fort Washington, PA), polymerized between Aclar embedding film sheets (Electron Microscopy Sciences, Fort Washington, PA) and mounted on resin blocks. Sections were then trimmed and cut at $100 \mathrm{~nm}$, mounted on copper grids, stained with uranyl acetate and lead citrate, and viewed under a Hitachi (Tokyo, Japan) EM 600 electron microscope at $75 \mathrm{kV}$. G-ratios (myelin sheath thickness/axon diameter) were determined on a total of 31 randomly selected normally myelinated or oligodendrocyte-remyelinated axons within regions of pathology. Random sampling was accomplished by measuring the G-ratio for only those axons bisected by horizontal grid lines digitally superimposed on $2000 \times$ digitally captured images. Measurements of myelin sheath thickness and axon diameter were conducted using Olympus MicroSuite B3SV software (Olympus America, Melville, NY).

Quantitative analysis. Total numbers of BrdU-labeled cells in the cervical region were quantified using unbiased stereological methods (Gundersen, 1986; Merrill et al., 2000), and the optical fractionator with StereoInvestigator software 5.05.1 was applied to an Olympus BX60 workstation. Three separate spinal cord regions were examined and quantified in each lesioned subject as follows: (1) the perilesion region on the lesioned side, containing regions of significant tissue degeneration and inflammation in which constituents of normal gray or white matter such as neurons or axons were not identifiable or were interspersed with damaged tissue; (2) the intact gray matter on the side contralateral to the lesion; and (3) the intact white matter on the side contralateral to the lesion. Cells within the lesion cavity were not quantified because this area was either devoid of cells or contained only fibrous connective scar that lacked neurons, axons, or glia. An estimate of the total number of BrdU+ cells in each of these regions was performed using five sections spaced equally apart over a $1.9 \mathrm{~mm}$ block spanning the lesion site. An adjusted sampling fraction was used to count at least 200 cells per spinal cord region as defined above, per animal. Upper and lower exclusion zones of $18.75 \%$ of section thickness were used. Cells were considered BrdUlabeled only if reaction product was clearly present within the nucleus with either a homogenous or clear punctate labeling pattern. The number of BrdU + cells was also quantified in the spinal cords of three lesioned subjects (subjects 2-4) at the L2 level in gray matter and white matter separately. Measures were taken on the side of the lumbar spinal 

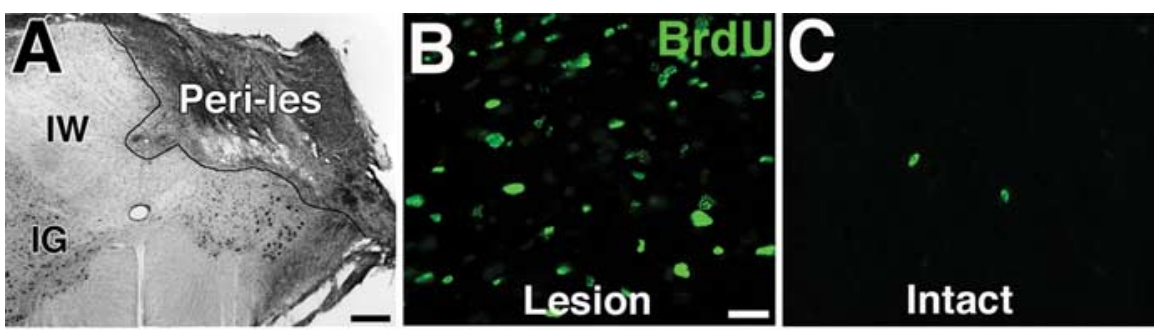

\section{D.BrdU Cell Density}

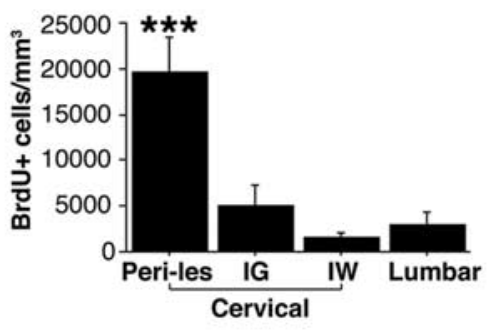

\section{E. BrdU Stereological} Cell Number

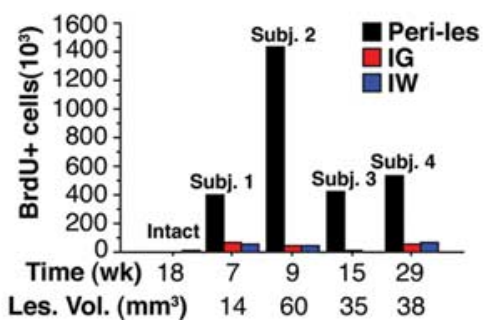

Figure 1. Lesion and BrdU labeling. $\boldsymbol{A}$, Nissl-stained section of $(6$ lesion site in subject 4, 7 months after injury. Peri-les, Perilesion tissue; IW, intact white matter; IG, intact gray matter. $\boldsymbol{B}$, Abundant BrdU labeling in perilesioned region of subject 4, 7 months after injury. $\boldsymbol{C}$, In contrast, intact subject exhibits only sparse BrdU labeling at $\mathbf{C} 6$ level. $\boldsymbol{D}$, Mean density of BrdU-labeled cells in four monkeys with C6-C7 spinal cord lesions. Extensive cell division occurs in perilesion region, and newly dividing cells are also evident on the contralateral, intact side of spinal cord and on lesioned side caudal to injury. Significantly more cells are present in perilesioned region than in other spinal cord areas $(p<0.001)$. $\boldsymbol{E}$, Total numbers of BrdU-labeled cells determined stereologically in each of four lesioned subjects at various time points after injury and in one intact monkey. Subj., Subject; Les. Vol., lesion volume. Scale bars: $\boldsymbol{A}, 720 \mu \mathrm{m}$; (in $\boldsymbol{B}) \boldsymbol{B}, \boldsymbol{C}, 20 \mu \mathrm{m}$. Error bars represent SEM.
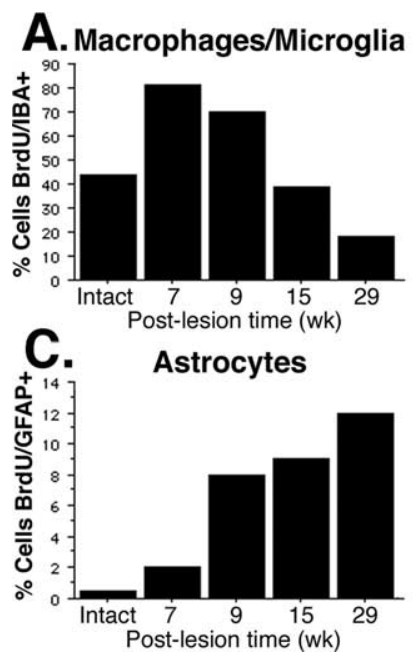
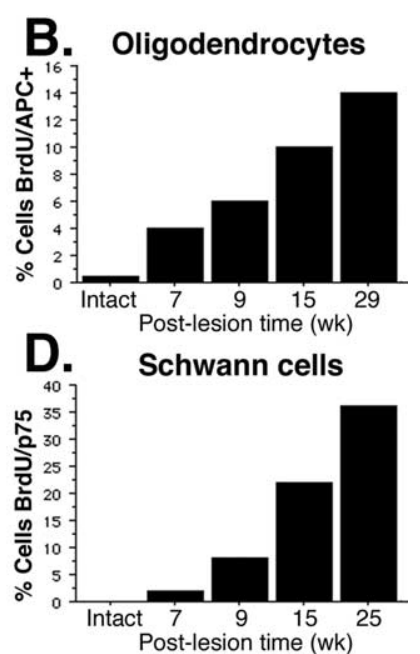

Figure 2. Fate of newly dividing cells. The proportion of inflammatory cells steadily diminishes over several weeks (wk) to months after injury $(\boldsymbol{A})$, whereas the proportion of cells expressing adult oligodendrocyte $(\boldsymbol{B})$, astrocyte $(\boldsymbol{C})$, and Schwann cell $(\boldsymbol{D})$ markers increases. Very few BrdU-labeled cells in the intact spinal cord express oligodendrocyte and astrocyte markers.

cord ipsilateral to the cervical lesion using the same stereological method described above. In the intact subject, all BrdU + cells were quantified in the C5 and L2 spinal cord in five separate sections at each level, equally spaced $1.9 \mathrm{~mm}$ apart. The quantified volumes were 60 and $58 \mathrm{~mm}^{3}$, respectively, at each level. BrdU+ cell numbers in gray and white matter were summed. Cell density was then calculated by dividing total cells into the spinal cord volume spanning the sampled region.

Quantification of double labeling for BrdU and phenotypic cell markers. Cells double labeled for BrdU and the other phenotypic markers used in this study were quantified. Sections were double labeled for BrdU and NeuN, MAP2, $\beta$-III-tubulin, IBA, APC, GFAP, p75, NG2, and vWF.

Because of the large number of phenotypic markers examined in this study (nine cellspecific labels per monkey, in addition to BrdU label and Nissl stain), there were not sufficient numbers of sections to conduct a stereological quantification for each label. Reliable estimates of the distribution of proportionate cell populations can however be derived by a sampling a total of $\sim 200$ cells per phenotypic label, using random sampling schemes and the exclusion zones used by the stereology software program (StereoInvestigator) (Peterson, 1999). We used this method in the present study to identify the proportion of BrdU-labeled cells expressing each phenotype-specific marker. Thus, for each double label of BrdU with a cell-specific marker, a minimum of $200 \mathrm{BrdU}+$ cells was counted in each of the three quantified regions (perilesion region, intact gray, intact white) in each subject, using confocal microscopy (Olympus Fluoview) and random sampling of fields at $400 \times$ magnification. The specificity of each label was first verified using single-channel scans that were then merged into multiplechannel views. To confirm double-labeling, confocal Z-stacks were generated. For quantification, sections were digitally scanned using 488 and 568 dual-laser channels. BrdU singlelabeled cells, and cells double labeled for BrdU and another specific marker, were recorded. For mature oligodendrocytes, 488, 568, and 647 triple-laser channels were used. Results for each marker are presented as the proportion of all BrdU + cells per region that are double labeled for BrdU and the label of interest. Two sections per animal were sampled from the immediate injury vicinity. Phenotypic analysis and quantification was performed at the C6 level in one intact monkey using methods described above. Oligodendrocytes in the lumbar corticospinal tract region were quantified in two sections per animal at $600 \times$ magnification, comparing lesioned and nonlesioned sides of the cord.

Imaging and statistical analysis. Images were processed using Adobe Photoshop 7.0 (Adobe Systems, San Jose, CA) or Volocity 3.0 (Improvision, Lexington, MA). To assess differences in the number of BrdUlabeled cells in various regions of the injured spinal cord (Fig. 1), ANOVA was used with a criterion of $p<0.05$ for significance.

\section{Results}

\section{Cell division after SCI}

SCI resulted in the recruitment of vast numbers of newly dividing cells to the perilesioned region of the spinal cord (Fig. 1): a mean of $19,500 \pm 3900 \mathrm{BrdU}$-labeled cells $/ \mathrm{mm}^{3}$ ( \pm SEM) was present in the lesioned region, an 81-fold increase compared with the number of BrdU-labeled cells at C6 in the intact monkey (240 cells $/ \mathrm{mm}^{3}$ ). The greatest number of cells, determined stereologically, was present in the subject with the largest lesion (Fig. $1 E$ ). Numbers of newly dividing cells were also increased in gray matter $\left(5000 \pm 2300 \mathrm{BrdU}\right.$-labeled cells $\left./ \mathrm{mm}^{3}\right)$ and white matter $\left(1500 \pm 500 \mathrm{BrdU}\right.$-labeled cells $\left./ \mathrm{mm}^{3}\right)$ contralateral to the lesion at $\mathrm{C} 6-\mathrm{C} 7$ among all subjects, compared with the intact animal (Fig. $1 E$ ). In the lumbar spinal cord ipsilateral to the cervical lesion, located several segments away from the lesion, numbers of newly dividing cells were also substantially increased to a mean of $3900 \pm 1400$ cells $/ \mathrm{mm}^{3}$ in contrast to $290 \mathrm{BrdU}$-labeled cells $/ \mathrm{mm}^{3}$ in the lumbar region of the intact subject. Most of the BrdUlabeled cells in the lumbar cord were present in tracts that contained descending, anterogradely degenerated axons, whereas relatively few BrdU-labeled cells were present in tracts containing 


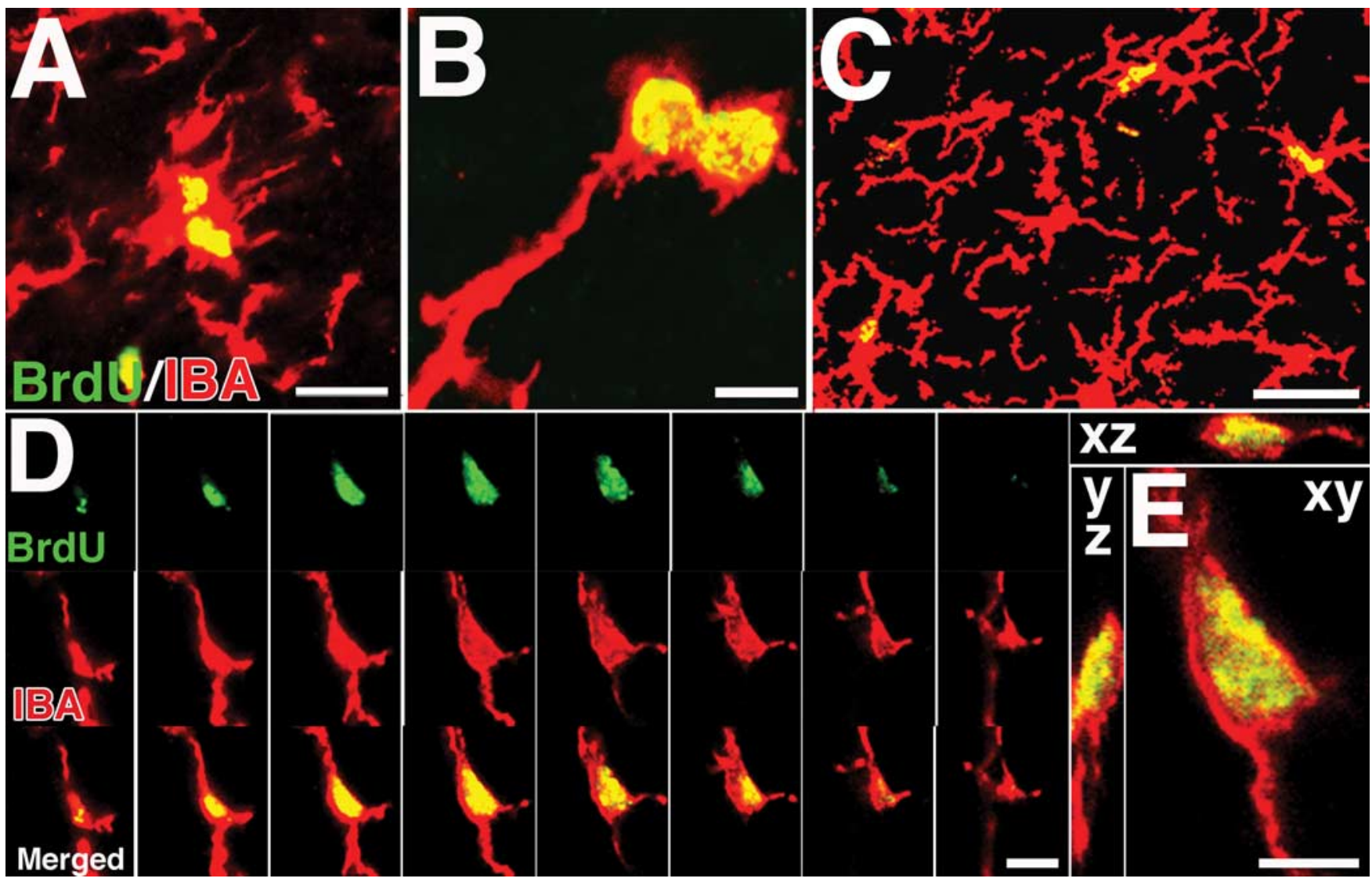

Figure 3. BrdU colocalization with microglial/macrophage markers 7 weeks after injury. $A, B$, Double-labeled microglial cells in perilesion region; pairing of BrdU-labeled nuclei in $B$ suggests cell division. C, Similar colocalization and pairing of BrdU-labeled cells in intact contralateral white matter. $\boldsymbol{D}, Z$-stack of BrdU/IBA double-labeled cell in perilesion region 7 months after lesion; $1 \mu \mathrm{m}$ separation. $\boldsymbol{E}, x y, x z$, and $y z$ plane images of typical double-labeled cell. Scale bars: $\boldsymbol{A}, 15 \mu \mathrm{m} ; \boldsymbol{B}, 5 \mu \mathrm{m} ; \boldsymbol{C}, 35 \mu \mathrm{m} ; \boldsymbol{D}, \boldsymbol{E}, 5 \mu \mathrm{m}$.

Table 2. Percentage of BrdU-labeled cells that express specific phenotypic markers on intact side of primate spinal cord, contralateral to lesion

\begin{tabular}{|c|c|c|c|c|c|c|c|c|}
\hline \multirow[b]{2}{*}{ Markers } & \multicolumn{2}{|l|}{ Subject 1} & \multicolumn{2}{|l|}{ Subject 2} & \multicolumn{2}{|l|}{ Subject 3} & \multicolumn{2}{|l|}{ Subject 4} \\
\hline & IG & IW & $\mathrm{IG}$ & IW & $\mathrm{IG}$ & IW & IG & IW \\
\hline IBA & $89 \pm 3 \%$ & $77 \pm 14 \%$ & $85 \pm 4 \%$ & $90 \pm 12 \%$ & $60 \pm 0.3 \%$ & $15 \pm 0.7 \%$ & $58 \pm 6 \%$ & $57 \pm 7 \%$ \\
\hline p75 & 0 & 0 & 0 & 0 & 0 & 0 & 0 & 0 \\
\hline vWF & $9 \pm 2 \%$ & $10 \pm 1 \%$ & $10 \pm 2 \%$ & $6 \pm 0.3 \%$ & $12 \pm 0.8 \%$ & $13 \pm 1 \%$ & $16 \pm 3 \%$ & $12 \pm 0.9 \%$ \\
\hline APC & $0.4 \pm 0.1 \%$ & $0.5 \pm 0.7 \%$ & $0.3 \pm 0.3 \%$ & $0.3 \pm 0.2 \%$ & 0 & 0 & $13 \pm 3 \%$ & $11 \pm 1 \%$ \\
\hline GFAP & 0 & 0 & 0 & 0 & 0 & 0 & $3 \pm 0 \%$ & $2 \pm 0.7 \%$ \\
\hline
\end{tabular}

IG, Gray matter; IW, white matter. Values are mean \pm SEM. Note: Totals are $<100 \%$ because not all BrdU-labeled cells express the markers indicated above.

rostrally projecting axons (e.g., the dorsal columns). Hence, BrdU labeling vastly increases adjacent to and remote from primate spinal cord lesion sites. The mean volume of the spinal cord perilesioned region was $37.1 \pm 10.3 \mathrm{~mm}^{3}$ in the four lesioned subjects; thus, a calculated mean of 725,000 newly dividing cells per monkey were generated as a result of SCI in the immediate injury zone.

\section{Identities of newly dividing cells}

The identities of newly dividing cells varied as a function of time after injury (Fig. 2). In all cases, cellular double labeling was verified by thin-plane confocal microscopy in $x y, x z$, and $y z$ planes. Within the perilesion region at the earliest time point of 7 weeks after injury, inflammatory cells comprised the majority of BrdUlabeled cells, with $81 \%$ of BrdU-containing cells coexpressing the macrophage/microglial marker IBA (Figs. 2, 3). The proportion of IBA-labeled cells gradually declined to $18 \%$ of all BrdU-labeled cells by 7 months after injury, and most IBA-labeled cells at this time point exhibited morphological features of resting microglia
(Fig. 3). A similar evolution of labeling was observed in contralateral, intact regions of the spinal cord (Table 2).

In contrast to the successive reduction over time in the proportion of BrdU-labeled cells expressing inflammatory-related markers after injury, the proportion of newly divided cells expressing mature oligodendrocyte and astrocyte markers sequentially increased from 7 weeks to 7 months after injury (Figs. 2, 4). To identify oligodendrocytes, sections were triple labeled for BrdU, APC (astrocytes/oligodendrocytes), and GFAP (astrocytes) (Fig. 4); cells that were BrdU positive/APC positive/GFAP negative (BrdU+/APC+/GFAP-) were identified as oligodendrocytes (McTigue et al., 2001). Although only 4\% of BrdUlabeled cells in the perilesion region exhibited markers of oligodendrocyte differentiation at 7 weeks after injury, the proportion of BrdU-labeled cells expressing mature oligodendrocyte markers increased to $15 \%$ by 7 months after injury (Figs. 2, 4). Parallel changes were observed in the contralateral, intact regions of the cord (Table 2). Electron microscopy indicated that spinal cord 


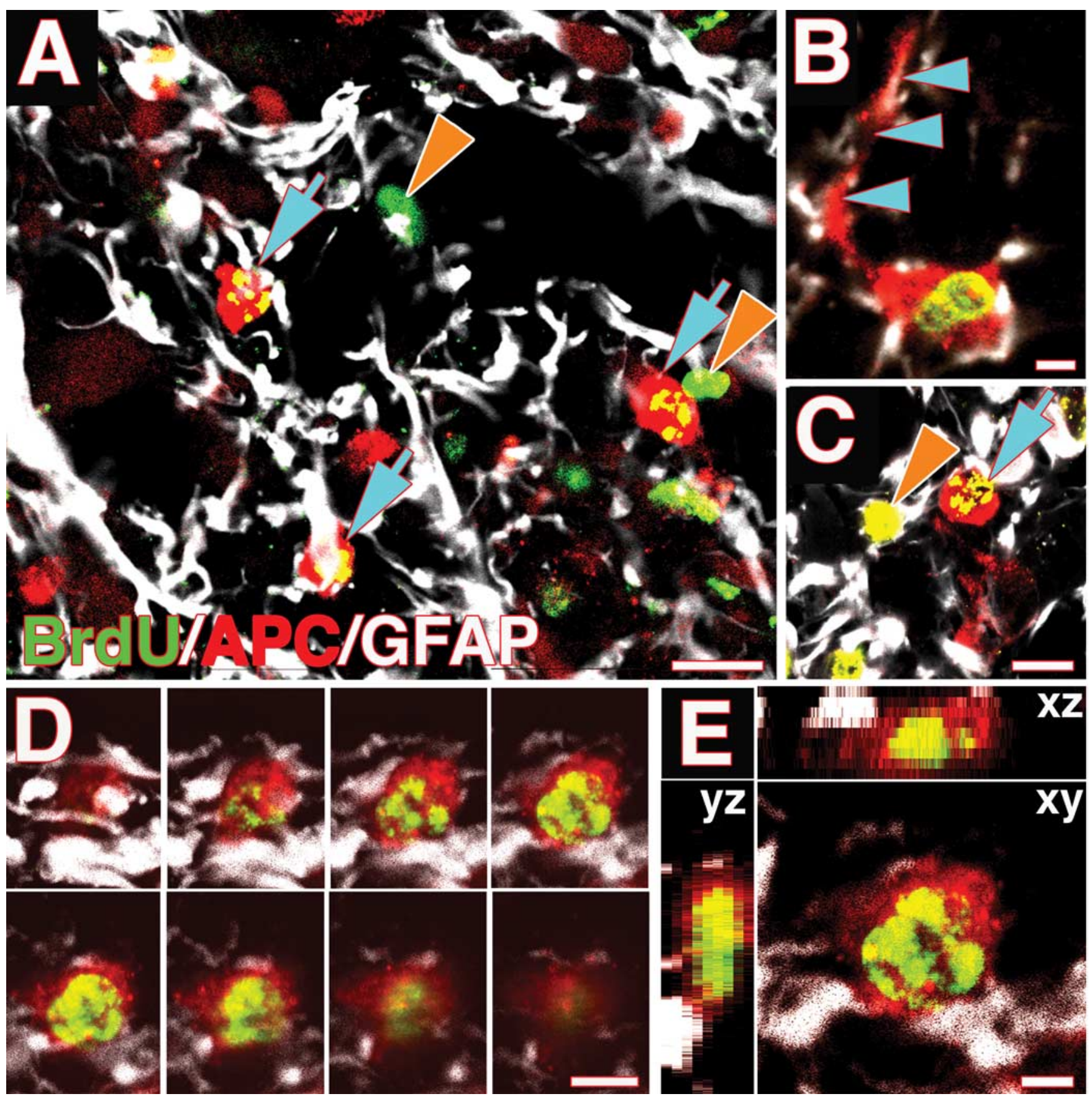

Figure 4. BrdU colocalization with mature oligodendrocyte markers. $A$, BrdU colocalizes with mature oligodendrocyte marker APC in perilesion region 7 months after injury; blue arrows indicate double-labeled cells, orange arrowheads indicate single BrdU-labeled cells. GFAP (white) is not colocalized with these cells. B, A BrdU/APC double-labeled cell from the C6 spinal cord contralateral to the lesion, exhibiting a long APC-labeled process (arrowheads) emanating from the cell body, indicating extension of APC label into myelinating segment of cell. $C$, BrdU/APC double-labeled cell (blue arrow) and BrdU/GFAP double-labeled cell (orange arrowhead) in perilesion region. $\boldsymbol{D}$, Confocal Z-stacks of BrdU/APC double-labeled cells; $1 \mu \mathrm{m}$ separation. $\boldsymbol{E}$, $x y, x z$, and $y z$ planes showing colocalization of BrdU with mature oligodendrocyte marker. Scale bars: $\boldsymbol{A}, 15 \mu \mathrm{m} ; \boldsymbol{B}, 5 \mu \mathrm{m} ; \boldsymbol{C}-\boldsymbol{E}, 10 \mu \mathrm{m}$.

segments surrounding the lesion site exhibited both demyelination and remyelination (Fig. 5). To ensure that oligodendrocyte remyelination could reliably be distinguished from normal myelination, we analyzed G-ratios (the ratio between the thickness of the myelin sheath and the diameter of the axon) for normally myelinated or oligodendrocyte-remyelinated axons. Oligodendrocyte-remyelinated axons were identified by their characteristically thin myelin sheaths relative to the diameter of the axons (Hildebrand and Hahn, 1978; Guy et al., 1989). Myelin sheath thickness in axons remyelinated by oligodendrocytes did not reach the thickness observed in normally myelinated axons. The mean G-ratio of oligodendrocyte-remyelinated axons, $5.32 \pm 1.3$ (16), was significantly less than the mean G-ratio of normally myelinated axons, $46.4 \pm 28.3$ (15) ( $p<0.01$; data are expressed as mean $\pm \mathrm{SD}$; numbers in parentheses indicate the number of axons scored). Thin-plane confocal imaging indicated that APClabeled extensions of BrdU-labeled cells in the perilesion region appeared to surround and ensheath axons (Fig. 5); many BrdUlabeled cells in these regions also exhibited colocalization of APC with myelin markers such as MOSP (Fig. 5A-C). These observa- 

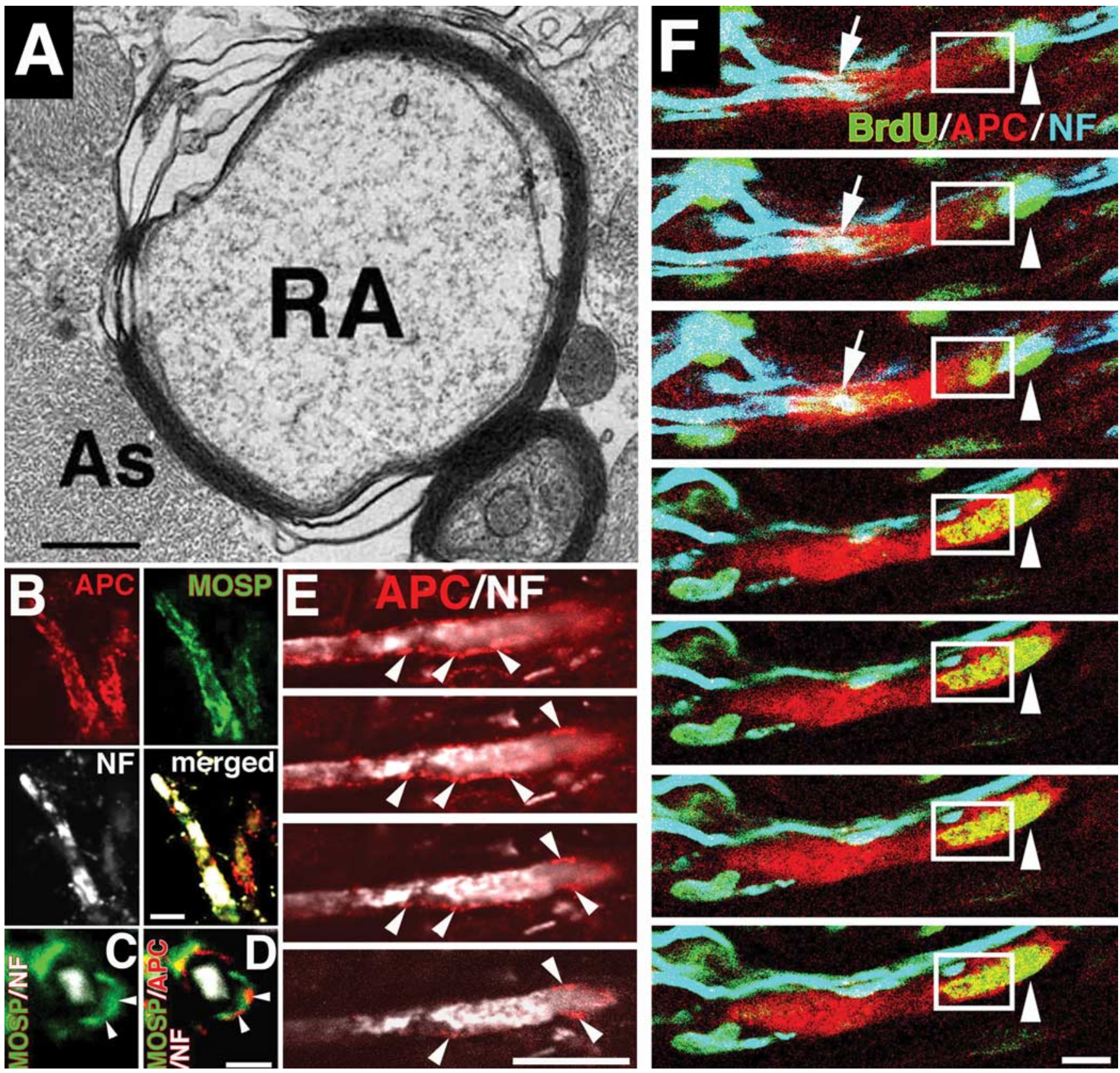

Figure 5. Demyelination and remyelination after primate $S C$ I. $A$, Electron photomicrograph of a remyelinated axon (RA) with a characteristically thin myelin sheath within ventrolateral white matter $2.5 \mathrm{~mm}$ caudal from lesion epicenter. An abundance of hypertrophic intermediate filament-rich astrocytic processes (As) surround the remyelinated axon. Scale bar, $0.5 \mu \mathrm{m}$. $\boldsymbol{B}-\boldsymbol{D}$, Triple labeling for APC, neurofilament (NF), and MOSP (labels oligodendrocytes and CNS myelin but not peripheral myelin). B, APC and MOSP labeling are evident surrounding NF-labeled axons in perilesion region, indicating that APC labeling can identify myelin around axons in lesioned regions. C, Images from unlesioned contralateral white matter show individual NF-labeled axon within MOSP-labeled myelin sheaths (arrowheads). D, APC (arrowheads) colocalizes with MOSP, indicating that APC labeling under high-resolution confocal microscopy can colocalize within rings of myelin that surround individual axons. $E$, An NF-labeled axon is surrounded by APC immunolabeling, suggesting ensheathment or myelination by an oligodendrocyte in the contralateral, intact region of the spinal cord. $\boldsymbol{F}$, Z-stack of a BrdU/APC double-labeled oligodendrocyte in longitudinal plane, showing an NF-labeled axon ensheathed by this cell (arrow) and, in subsequent Z-sections, the same cell showing continuity of APC-labeling with a BrdU-labeled nucleus (within square). Each image is $0.5 \mu \mathrm{m}$ thick, and images span a total range of $7.0 \mu \mathrm{m}$. Thus, newly born cells after primate SCl express markers associated with mature oligodendrocytes and appear to ensheath or myelinate axons. An oligodendrocyte nucleus of an adjacent cell, also BrdU labeled, is indicated by the arrowhead. Scale bars: $\boldsymbol{B}-\boldsymbol{F}, 10 \mu \mathrm{m}$.

tions suggest that a proportion of newly dividing cells after primate SCI exhibit anatomical and immunocytochemical characteristics of functional oligodendrocytes.

The proportion of BrdU-labeled cells expressing markers of mature astrocytes increased from $2 \%$ at 7 weeks after injury to $12 \%$ by 7 months after injury in the perilesion region, with parallel changes in the contralateral, intact regions (Figs. 2, 6, Table
2). Hence, new cell division repopulates glial cells around the injury site after primate SCI.

Oligodendrocyte cell death occurs at spinal levels remote from injury sites via apoptotic mechanisms (Crowe et al.,1997). Consistent with this finding, we observed fragmented cell nuclei in the lumbar spinal cord, remote from the lesion site, by both Nissl and Hoechst staining (supplemental Fig. 1, available at www. 

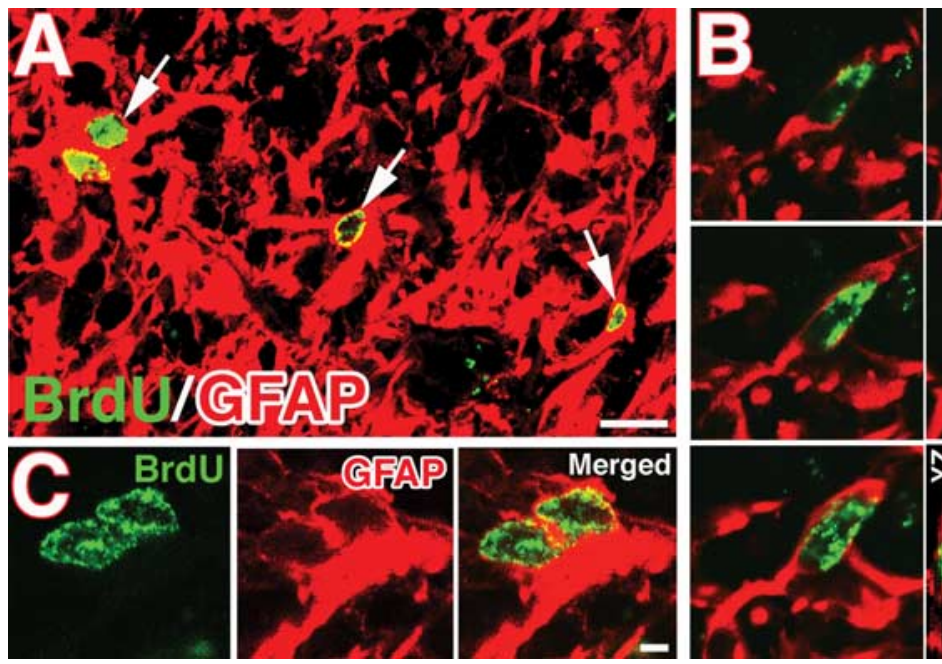

Figure 6. Newly born astrocytes at sites of SCI. $\boldsymbol{A}$, BrdU/GFAP double-labeled astrocytes in perilesion region (arrows) 9 weeks after injury. $\boldsymbol{B}$, Z-stack of BrdU/GFAP double-labeled astrocyte indicates cellular colocalization; $1 \mu \mathrm{m}$ separation. $\boldsymbol{C}$, Two BrdUlabeled nuclei are colocalized with cytoplasmic GFAP in perilesion region. Juxtaposition of nuclei and cytoplasm may indicate active or recent cell division. $\boldsymbol{D}, x y, x z$, and $y z$ views of the BrdU/GFAP double-labeled astrocyte, as shown in $\boldsymbol{B}$. Scale bars: $\boldsymbol{A}, 15$ $\mu \mathrm{m} ; \boldsymbol{B}, \boldsymbol{C}, 5 \mu \mathrm{m}$.

jneurosci.org as supplemental material). Most apoptotic cells were located in lumbar tracts subjected to anterograde axonal injury after the cervical lesion. Indeed, the number of APCpositive/GFAP-negative oligodendrocytes was reduced by $55 \pm$ $4 \%$ in the lumbar corticospinal tract after cervical hemisection compared with the contralateral, intact side. Many BrdU-labeled cells in degenerating lumbar tracts exhibited extensive colocalization with microglial and astrocyte cell markers (supplemental Fig. 1, available at www.jneurosci.org as supplemental material). Ascending tracts, such as the dorsal columns, did not contain fragmented cell nuclei on Nissl and Hoechst staining and, correspondingly, contained rare BrdU-labeled cells. Most apoptotic cell profiles were evident at earlier time points of 7 weeks to 15 weeks after injury, whereas the subject surviving for 7 months showed few apoptotic cells.

NG2-expressing oligodendrocyte progenitor cells have been reported previously to proliferate early (2 weeks) after rodent SCI (McTigue et al., 2001). In this study, we observed only rare cells double labeled for BrdU and NG2, bearing multiple processes typical of oligodendrocyte progenitor cells (Horner et al., 2000; Jones et al., 2002) (Fig. 7). These cells were present only 7 and 9 weeks after lesion, suggesting that peak responses of this oligodendrocyte progenitor cell population occur earlier than the 7 week postinjury time point examined in this long-term study.

Newly generated cells after injury did not form lasting neurons. Double labeling for BrdU and the neuron-specific markers NeuN, MAP2, and $\beta$-III-tubulin showed no colocalization, indicating an absence of spontaneous neuronal differentiation and repopulation after SCI. Occasional cells demonstrated pseudocolocalization of BrdU with neuronal markers in $40-\mu \mathrm{m}$-thick sections, but thin-section confocal analysis failed to disclose true colocalization of BrdU with these neuronal markers.

\section{Other cell types}

Schwann cells extensively infiltrate sites of SCI in rodents (Matthews et al., 1979; Beattie et al.,1997). Robust Schwann cell invasion of the perilesion region was also observed in the primate spinal cord based on p75 somal labeling in cells bearing the spindle-shaped morphology of Schwann cells (Fig. 7). Many of
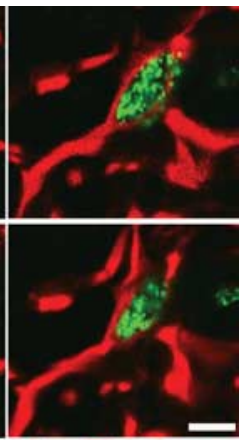

used in this study.

these p75-expressing, spindle-shaped cells colocalized with BrdU, indicating that Schwann cells divide and migrate into the lesion site. Colocalization of BrdU with the endothelial cell marker vWF suggests that vascular cells also proliferate after SCI (Fig. 7).

\section{Cell division in the intact animal}

A total of 240 BrdU-labeled cells $/ \mathrm{mm}^{3}$ were detected at the C6 level of the spinal cord in one intact monkey 18 weeks after BrdU injection. Phenotypic analysis revealed that $44 \%$ of BrdU-labeled cells in this animal expressed the microglial marker IBA, and $41 \%$ of cells expressed the vascular marker vWF. Cells double labeled for oligodendrocytes and astrocytes were rare, constituting $<1 \%$ of all BrdU-labeled cells in the intact spinal cord. Neither Schwann cells nor NG2 expressing cells were detected in this subject. Remaining BrdU-labeled cells $(\sim 14 \%)$ did not colocalize with any of the phenotypic markers

\section{Discussion}

These findings reveal that robust endogenous cell division occurs after primate SCI. There are two long-term consequences of this spontaneous cell division: (1) a subpopulation of newly dividing cells adopt mature oligodendrocyte markers in regions of demyelination, appearing to ensheath or remyelinate axons, and (2) new astrocytes are generated, a phenomenon that is likely to be important for reestablishing parenchymal stability and the blood-brain barrier after injury (Sofroniew, 2000; Faulkner et al., 2004). Of note, primate SCI does not result in new neuron formation derived from cells dividing within $5 \mathrm{~d}$ of injury. These findings reveal previously unknown endogenous mechanisms for glial replacement after primate SCI that may reduce outcome severity, particularly after incomplete injury.

The major findings of this study are based on the examination of four lesioned subjects, all males, who received lesions of the right side of the spinal cord. Lesion volume was varied between subjects, and survival times ranged from 7 weeks to 7 months after injury. Yet, findings were highly consistent between subjects; that is, the proportion of BrdU-labeled cells colocalizing with inflammatory markers consistently and steadily diminished from 7 weeks to 7 months after injury, whereas the proportion of BrdU-labeled cells colocalizing with astrocytic, oligodendrocyte, and Schwann cell markers consistently and steadily increased around the lesion site over the same time period. Variability of the data were minimized by use of stereological quantification of BrdU cell numbers and random and corrected sampling methods for determination of the phenotype of BrdU-labeled cells. Thus, differences in lesion size between subjects were accounted for in the analyses we used, and larger lesions appeared to increase the total number but not the phenotypic fate of BrdU-labeled cells.

There is a decrease in the density of BrdU-labeled cells (in cells per cubic millimeter) in the perilesioned region from 7 weeks $\left(28,700 / \mathrm{mm}^{3}\right)$ to 7 months $\left(14,100 / \mathrm{mm}^{3}\right)$ after lesion (calculated from data in Fig. $1 E$ ). This decrease of BrdU cell density is likely attributable to the clearing of BrdU-labeled inflammatory cells from the perilesioned region, although it may also partially 


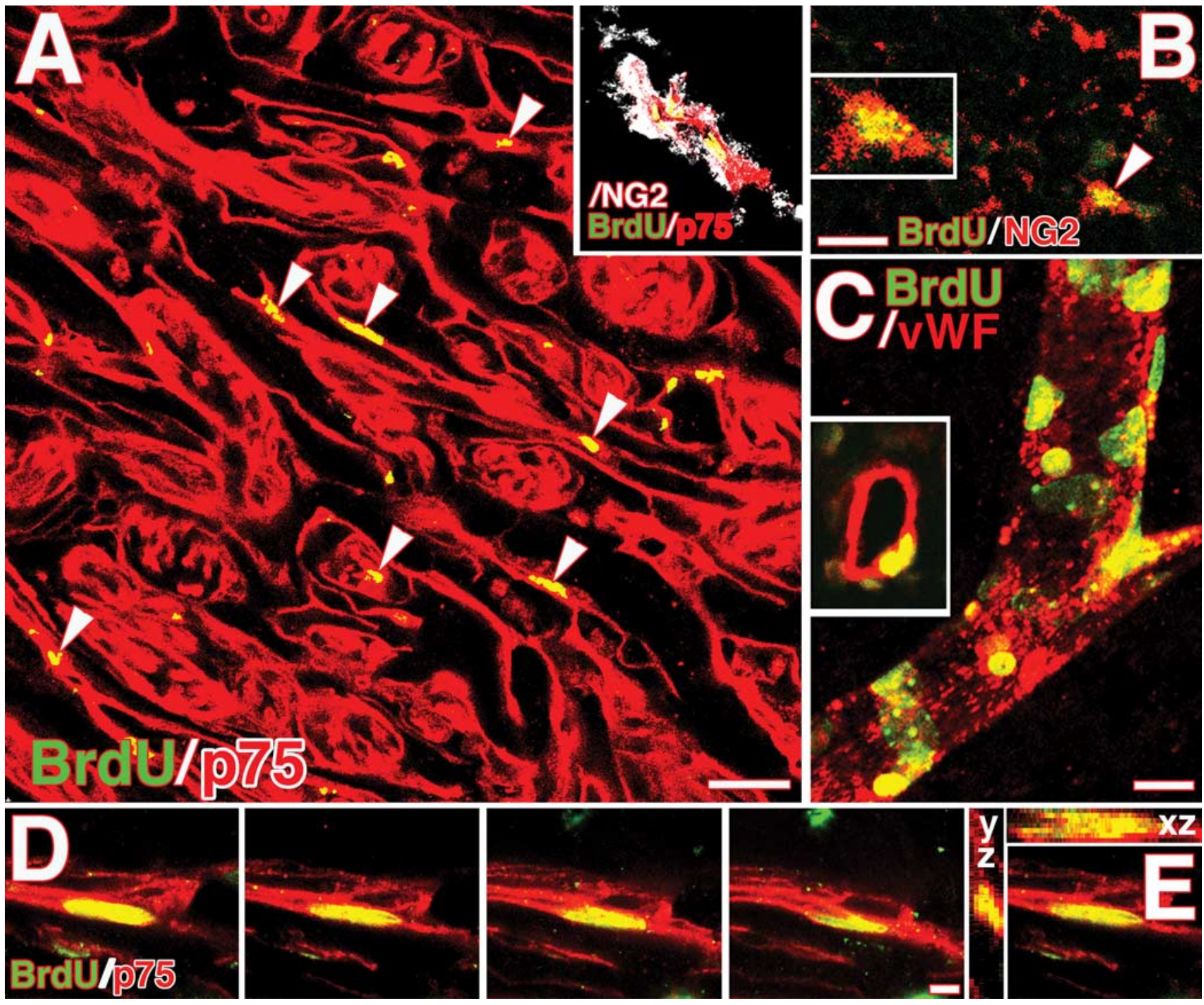

Figure 7. Proliferation of Schwann cells and vascular cells. A, BrdU/p75 double-labeled cells (arrowheads) in perilesion region. Elongated soma of p75-labeled cells suggests that Schwann cells migrate into the lesioned region, as commonly observed in rodent studies (see Results). Inset, BrdU/p75 cells from perilesion region express NG2 on the cell surface, as reported previously on Schwann cells after rodent experimental SCI (Jones et al., 2003). B, BrdU/NG2 double-labeled cells (arrowheads). Such cells were rare and present only on the edge of the perilesion region 7 and 9 weeks after lesion. C, BrdU/vWF double-labeled endothelial cells on blood vessels and capillaries in perilesion region. Inset shows capillary cross-section. $\boldsymbol{D}, Z$-scans indicate colocalization of BrdU with p75 in perilesion region ( $2 \mu \mathrm{m}$ separation). $\boldsymbol{E}, x y, y z$, and $x z$ views of the BrdU/p75 double-labeled Schwann cell, as shown in $\boldsymbol{D}$. Scale bars: $\boldsymbol{A}, 35 \mu \mathrm{m} ; \boldsymbol{B}, 20 \mu \mathrm{m} ; \boldsymbol{C}, 10 \mu \mathrm{m} ; \boldsymbol{D}, \boldsymbol{E}(X Y$ plane), 5 $\mu \mathrm{m} ; \boldsymbol{E}$ ( $X Z$ and $Y Z$ planes), $2.5 \mu \mathrm{m}$.

result from dilution of BrdU below limits of detection after several cycles of cell division. Whereas the density of BrdU-labeled inflammatory cells diminishes at progressive time points after injury, the percentage of oligodendrocytes and astrocytes increases. This proportionate increase in newly generated glia could be caused either by the clearing of BrdU-labeled inflammatory cells or to continued maturation of glia over very extended time periods after injury. Calculation of the density of BrdU-labeled glial cells per cubic millimeter in perilesioned tissue at successive time points after injury (calculated from data in Fig. $1 E$ ) reflects no distinct trend toward a continuing increase in either BrdUlabeled oligodendrocytes or astrocytes after injury, tentatively suggesting that most glial genesis may be established by 7 weeks after injury. However, additional studies would be required to clearly address this point.

The pattern of recovery from injury to the brains and spinal cords of nonhuman primates parallels, in some respects, obser- vations in humans: complete or extensive lesions of a system are rarely followed by substantial functional recovery, whereas partial lesions are often accompanied by a substantial degree of functional recovery (Turner, 1891; Mott, 1892; Mettler, 1944; Lassek and Anderson, 1961; Kuypers, 1974; Schwartzman, 1978; Little and Halar, 1985; Roth et al., 1991; Nathan, 1994; Coleman and Geisler, 2004) that is paralleled by systems-level plasticity (Netz and Homberg, 1997; Marshall et al., 2000; Schmidlin et al., 2004). Partial lesions that spare some pathways provide a potential substrate for subsequent spontaneous plasticity in the form of sprouting of spared axons or modified use of spared projections, which could lead to functional improvement. In the case of SCI, a component of the functional deficit after injury is thought to be attributable to demyelination of spared axons (Griffiths and McCulloch, 1983; Waxman, 1992; Bunge et al., 1994; Cao et al., 2001), and the present findings suggest that remyelination of spared projections by newly generated oligodendrocytes could 
contribute to recovery. Previous studies suggest that embryonic stem cells, when implanted into the spinal cord, differentiate into oligodendrocytes and remyelinate host axons (Keirstead et al., 2005). Our findings indicate that the injured spinal cord environment could facilitate stem cell differentiation along glial lineages. A preference for glial differentiation has also been reported in the few studies examining cell division in the intact adult rodent spinal cord: newly dividing cells in the intact rodent spinal cord adopt glial but not neuronal fates (Horner et al., 2000) and, indeed, cues in the intact spinal cord appear to specifically favor glial rather than neuronal cell-type differentiation (Shihabuddin et al., 2000; Song et al., 2002). In addition to a potential role of oligodendrocyte differentiation in supporting recovery after primate SCI, astrocytic differentiation observed in this study could also contribute to recovery. Immature astrocytes facilitate axon outgrowth (Smith et al., 1990) and recovery of the CNS from injury requires astrocyte activation (Sofroniew, 2000; Faulkner et al., 2004; Smith et al., 1990). In agreement with the present findings, a previous study also reported extensive glial differentiation (Zai and Wrathall, 2005) of newly born cells after contusive SCI in rats.

This study demonstrates that newly divided cells within $5 \mathrm{~d}$ of injury are abundant near sites of primate SCI and that the longterm fate of many of these cells is to repopulate glia. It is possible that experimental augmentation of endogenous stem cell responses could increase recovery after SCI. For example, a recent report in a rodent model indicated that Neurogenin-2 exposure increased neuronal differentiation by stem cells (Hofstetter et al., 2005), raising the possibility of neuronal replacement at sites of SCI. Future experimental approaches could attempt to increase the number and modify the fate of differentiating endogenous stem cells.

\section{References}

Barbeau H, Fung J, Leroux A, Ladouceur M (2002) A review of the adaptability and recovery of locomotion after spinal cord injury. Prog Brain Res 137:9-25.

Bareyre FM, Kerschensteiner M, Raineteau O, Mettenleiter TC, Weinmann O, Schwab ME (2004) The injured spinal cord spontaneously forms a new intraspinal circuit in adult rats. Nat Neurosci 7:269-277.

Beattie MS, Bresnahan JC, Komon J, Tovar CA, Van Meter M, Anderson DK, Faden AI, Hsu CY, Noble LJ, Salzman S, Young W (1997) Endogenous repair after spinal cord contusion injuries in the rat. Exp Neurol 148:453-463.

Bhat RV, Axt KJ, Fosnaugh JS, Smith KJ, Johnson KA, Hill DE, Kinzler KW, Baraban JM (1996) Expression of the APC tumor suppressor protein in oligodendroglia. Glia 17:169-174.

Bunge MB, Holets VR, Bates ML, Clarke TS, Watson BD (1994) Characterization of photochemically induced spinal cord injury in the rat by light and electron microscopy. Exp Neurol 127:76-93.

Cao QL, Zhang YP, Howard RM, Walters WM, Tsoulfas P, Whittemore SR (2001) Pluripotent stem cells engrafted into the normal or lesioned adult rat spinal cord are restricted to a glial lineage. Exp Neurol 167:48-58.

Coleman WP, Geisler FH (2004) Injury severity as primary predictor of outcome in acute spinal cord injury: retrospective results from a large multicenter clinical trial. Spine J 4:373-378.

Crowe MJ, Bresnahan JC, Shuman SL, Masters JN, Beattie MS (1997) Apoptosis and delayed degeneration after spinal cord injury in rats and monkeys. Nat Med 3:73-76.

Dyer CA, Matthieu JM (1994) Antibodies to myelin/oligodendrocytespecific protein and myelin/oligodendrocyte glycoprotein signal distinct changes in the organization of cultured oligodendroglial membrane sheets. J Neurochem 62:777-787.

Faulkner JR, Herrmann JE, Woo MJ, Tansey KE, Doan NB, Sofroniew MV (2004) Reactive astrocytes protect tissue and preserve function after spinal cord injury. J Neurosci 24:2143-2155.

Galea MP, Darian-Smith I (1997) Corticospinal projection patterns follow- ing unilateral section of the cervical spinal cord in the newborn and juvenile macaque monkey. J Comp Neurol 381:282-306.

Goldberger ME (1974) Functional recovery after lesions of the nervous system. IV. Structural correlates of recovery in adult subjects. Recovery of function and collateral sprouting in cat spinal cord. Neurosci Res Program Bull 12:235-239.

Griffiths IR, McCulloch MC (1983) Nerve fibres in spinal cord impact injuries. Part 1 . Changes in the myelin sheath during the initial 5 weeks. J Neurol Sci 58:335-349.

Gundersen HJ (1986) Stereology of arbitrary particles. A review of unbiased number and size estimators and the presentation of some new ones, in memory of William R. Thompson. J Microsc 143:3-45.

Guy J, Ellis EA, Kelley K, Hope GM (1989) Spectra of G ratio, myelin sheath thickness, and axon and fiber diameter in the guinea pig optic nerve. J Comp Neurol 287:446-454.

Hildebrand C, Hahn R (1978) Relation between myelin sheath thickness and axon size in spinal cord white matter of some vertebrate species. J Neurol Sci 38:421-434.

Hill CE, Proschel C, Noble M, Mayer-Proschel M, Gensel JC, Beattie MS, Bresnahan JC (2004) Acute transplantation of glial-restricted precursor cells into spinal cord contusion injuries: survival, differentiation, and effects on lesion environment and axonal regeneration. Exp Neurol 190:289-310

Hofstetter CP, Holmstrom NA, Lilja JA, Schweinhardt P, Hao J, Spenger C, Wiesenfeld-Hallin Z, Kurpad SN, Frisen J, Olson L (2005) Allodynia limits the usefulness of intraspinal neural stem cell grafts; directed differentiation improves outcome. Nat Neurosci 8:346-353.

Horner PJ, Power AE, Kempermann G, Kuhn HG, Palmer TD, Winkler J, Thal LJ, Gage FH (2000) Proliferation and differentiation of progenitor cells throughout the intact adult rat spinal cord. J Neurosci 20:2218-2228.

Jones LL, Yamaguchi Y, Stallcup WB, Tuszynski MH (2002) NG2 is a major chondroitin sulfate proteoglycan produced after spinal cord injury and is expressed by macrophages and oligodendrocyte progenitors. J Neurosci 22:2792-2803.

Jones LL, Sajed D, Tuszynski MH (2003) Axonal regeneration through regions of chondroitin sulfate proteoglycan deposition after spinal cord injury: a balance of permissiveness and inhibition. J Neurosci 23:9276-9288.

Keirstead HS, Nistor G, Bernal G, Totoiu M, Cloutier F, Sharp K, Steward O (2005) Human embryonic stem cell-derived oligodendrocyte progenitor cell transplants remyelinate and restore locomotion after spinal cord injury. J Neurosci 25:4694-4705.

Kuypers HG (1974) Functional recovery after lesions of the nervous system. IV. Structural correlates of recovery in adult subjects. Recovery of motor function in rhesus monkeys. Neurosci Res Program Bull 12:240-244.

Lassek AM, Anderson PA (1961) Motor function after spaced contralateral hemisections in the spinal cord. Neurology 11:362-365.

Little JW, Halar E (1985) Temporal course of motor recovery after BrownSequard spinal cord injuries. Paraplegia 23:39-46.

Marshall RS, Perera GM, Lazar RM, Krakauer JW, Constantine RC, DeLaPaz RL (2000) Evolution of cortical activation during recovery from corticospinal tract infarction. Stroke 31:656-661.

Matthews MA, St Onge MF, Faciane CL, Gelderd JB (1979) Spinal cord transection: a quantitative analysis of elements of the connective tissue matrix formed within the site of lesion following administration of piromen, cytoxan or trypsin. Neuropathol Appl Neurobiol 5:161-180.

McDonald JW, Liu XZ, Qu Y, Liu S, Mickey SK, Turetsky D, Gottlieb DI, Choi DW (1999) Transplanted embryonic stem cells survive, differentiate and promote recovery in injured rat spinal cord. Nat Med 5:1410-1412.

McTigue DM, Wei P, Stokes BT (2001) Proliferation of NG2-positive cells and altered oligodendrocyte numbers in the contused rat spinal cord. J Neurosci 21:3392-3400.

Merrill DA, Roberts JA, Tuszynski MH (2000) Conservation of neuron number and size in entorhinal cortex layers II, III, and V/VI of aged primates. J Comp Neurol 422:396-401.

Mettler FA (1944) Observation on the consequences of large, subtotal lesion of the simian spinal cord. J Comp Neurol 81:339-360.

Mott FW (1892) Result of hemisection of the spinal cord in monkey. Tr Roy Soc London B 13:1-15.

Nathan PW (1994) Effects on movement of surgical incisions into the human spinal cord. Brain 117:337-346. 
Netz JLT, Homberg V (1997) Reorganization of motor output in the nonaffacted hemisphere after stroke. Brain 120:1579-1586.

Peterson DA (1999) Quantitative histology using confocal microscopy: implementation of unbiased stereology procedures. Methods 18:493-507.

Pfeifer K, Vroemen M, Blesch A, Weidner N (2004) Adult neural progenitor cells provide a permissive guiding substrate for corticospinal axon growth following spinal cord injury. Eur J Neurosci 20:1695-1704.

Roth EJ, Park T, Pang T, Yarkony GM, Lee MY (1991) Traumatic cervical Brown-Sequard and Brown-Sequard-plus syndromes: the spectrum of presentations and outcomes. Paraplegia 29:582-589.

Schmidlin E, Wannier T, Bloch J, Rouiller EM (2004) Progressive plastic changes in the hand representation of the primary motor cortex parallel incomplete recovery from a unilateral section of the corticospinal tract at cervical level in monkeys. Brain Res 1017:172-183.

Schwartzman RJ (1978) A behavioral analysis of complete unilateral section of the pyramidal tract at the medullary level in Macaca mulatta. Ann Neurol 4:234-244.

Shihabuddin LS, Horner PJ, Ray J, Gage FH (2000) Adult spinal cord stem cells generate neurons after transplantation in the adult dentate gyrus. J Neurosci 20:8727-8735.
Smith GM, Rutishauser U, Silver J, Miller RH (1990) Maturation of astrocytes in vitro alters the extent and molecular basis of neurite outgrowth. Dev Biol 138:377-390.

Sofroniew MV (2000) Astrocyte failure as a cause of CNS dysfunction. Mol Psychiatry 5:230-232.

Song H, Stevens CF, Gage FH (2002) Astroglia induce neurogenesis from adult neural stem cells. Nature 417:39-44.

Turner WA (1891) On hemisection of the spinal cord. Brain 14:496.

Vroemen M, Aigner L, Winkler J, Weidner N (2003) Adult neural progenitor cell grafts survive after acute spinal cord injury and integrate along axonal pathways. Eur J Neurosci 18:743-751.

Waxman SG (1992) Demyelination in spinal cord injury and multiple sclerosis: what can we do to enhance functional recovery? J Neurotrauma 9 [Suppl 1]:S105-S117.

Weidner N, Ner A, Salimi N, Tuszynski MH (2001) Spontaneous corticospinal axonal plasticity and functional recovery after adult central nervous system injury. Proc Natl Acad Sci USA 98:3513-3518.

Zai LJ, Wrathall JR (2005) Cell proliferation and replacement following contusive spinal cord injury. Glia 50:247-257. 